[DOI: 10.24214/jecet.A.8.3.27380.]

Juurnal of Environmental Science, Computer Science and Engineering \& Technology

An International Peer Review E-3 Journal of Sciences and Technology

Available online at www.jecet.org

Section A: Environmental Science

Research Article

\title{
Regularity of dynamics of medium width of leaves of a birch at the growth maximum in the period of vegetation 2018
}

\author{
Mazurkin P.M ${ }^{1}$ and Kudryashova A.I ${ }^{2}$. \\ ${ }^{1}$ Dr. Sc., Prof., Volga State University of Technology, Yoshkar-Ola, Russia, \\ ${ }^{2}$ S. lec., Volga State University of Technology, Yoshkar-Ola, Russia,
}

Received: 30 June 2019; Revised: 15 July 2019; Accepted: 25 July 2019

\begin{abstract}
It is shown that the achievement of the maximum of the average width of the birch leaves is a great bioindicator of environmental quality. Moreover, the quality assessment can be carried out with-out measuring the concentration of pollution. According to patent 2606189 for the invention on the side at an altitude of $1.5-2.0 \mathrm{~m}$ from the prevailing winds on the dynamics from July 15 to September 23, 2018 , the average width of 10 leaves near the road was measured. The parameters of the model with two components showed that the half-period of oscillation at the beginning of the growing season for 10 birches varies from 1.32 to 21.35 days. All models of dynamics are the same in design, but have a different character. The growing season near the maximum growth affects with a correlation coefficient of more than 0.999 , so the behavior of 10 leaves has a high quantum certainty. To assess the behavior of groups of leaves, a new criterion was introduced - the coefficient of dynamism equal to the ratio of the difference between the fact and the trend to the fact of the average width of the leaves of the birch. The maximum width of the leaves and gave the highest values of the coefficient of dynamism. This criterion allows to rank the birch in descending order of the influence of vibrations from affecting the surrounding of the birch environment.
\end{abstract}

Keywords: vegetation, prevailing winds, 10 birch, 10 account of leaves, width, dynamics, oscillatory adaptation, the dynamic factor, patterns 


\section{INTRODUCTION}

The evolution of the earth's climate for geological terms is largely due to variations in total solar radiation $^{1}$ and changes in the content of greenhouse gases in the atmosphere. Climate change affects the vegetation of the Earth ${ }^{2}$.

The expansion of terrestrial plants, together with the ocean, has made it possible to ensure long-term habitability on the planet. Mankind uses fossil fuels, by the middle of the XXI century, the value of $\mathrm{CO}_{2}$ will be the same as the early Eocene (50 million years ago). If the $\mathrm{CO}_{2}$ concentration continues to rise in the XXIII century, the earth will react as one and a half billion years ${ }^{3}$.

Understanding the response of plants to environmental factors is necessary to predict changes in the rate of carbon uptake in forests under different environmental conditions. In Finland, there is an indication of the reaction of young deciduous trees to rising air temperatures in interaction with tropospheric ozone. This knowledge increases the chances of developing models to include parameters that describe the forest system in changing climatic conditions ${ }^{4}$. It can be argued that the future of $\mathrm{CO}_{2}$ containment lies in increasing the area, primarily forests ${ }^{5,6}$.

The temperature dynamics ${ }^{7}$ can be described by a set of asymmetric wavelets (a set of quanta of behavior) up to the measurement error. Similarly, the $\mathrm{CO}_{2}$ content in the atmosphere is well quantized. The dynamics of carbon in Europe changes according to wavelets of universal design ${ }^{8,9}$. Forecast V. Zharkova ${ }^{10}$ on small ice age in the 2030-2040 us confirmed. It will start in 2032 and continue until 2046.

In ecological technologies with the use of birch leaves gradually comes the understanding of the need to simulate the mutual relations between the parameters of the structure of plant leaves by identification $^{8}, 11,12$, This invention relates to the engineering of biology and bioindication of the environment quality measurements of the growth of the organs of different plant species, mostly woody plants, for example, samples in the form of leaves of birch trees without cutting them with a simple and small leaf blades.

The purpose of the article is to improve the accuracy of the indication of the quality of the surrounding birch leaves of the local environment under patent 2606189 for the invention on the side at an altitude of $1.5-2.0 \mathrm{~m}$ from the prevailing winds over the dynamics from July 15 to September 23,2018 , the average width of 10 leaves near the road with heavy traffic cars.

\section{MATERIALS AND METHODS}

Plant growth is a complex process, it is based on such fundamental phenomena as rhythm, polarity, differentiation, irritability, correlation. These processes are common for ontogenesis of living organisms. Ontogenesis - individual development of the body from zygote (or vegetative germ) to natural death. Thanks to the active activity of meristems and photosynthetic activity of leaves, the green plant acquires a number of features that characterize its growth. In the process of plant ontogenesis growth is observed during the main stages of its life cycle ${ }^{10,13,14}$. Therefore, in further studies it is possible to identify patterns of influence of meteorological parameters on the dynamics of vegetative organs of plants.

Table 1 shows the average widths for 10 leaves taken without cutting and measured from 15 July to 23 September 2018. A total of 18 rows. The first point on May 01 in 2018 was the beginning of the growing season, so put 0 . 
Table 1: The average width of 10 leaves of birch hanging for Yoshkar-Ola

\begin{tabular}{|c|c|c|c|c|c|c|c|c|c|c|c|}
\hline Date & $\begin{array}{c}\text { Time } \\
t \text {, day }\end{array}$ & $\begin{array}{c}\text { Lebedev } \\
\text { Street }\end{array}$ & $\begin{array}{c}\text { Voskresensky } \\
\text { prospect }\end{array}$ & $\begin{array}{c}\text { Street } \\
\text { Eshkinina }\end{array}$ & $\begin{array}{c}\text { Lenin } \\
\text { avenue }\end{array}$ & $\begin{array}{c}\text { Chawain } \\
\text { Boulevard }\end{array}$ & $\begin{array}{c}\text { Panfilov } \\
\text { Street }\end{array}$ & $\begin{array}{c}\text { K.Marx } \\
\text { Street }\end{array}$ & $\begin{array}{c}\text { Builders } \\
\text { Street }\end{array}$ & $\begin{array}{c}\text { Botanical } \\
\text { garden }\end{array}$ & $\begin{array}{c}\text { Osipenko } \\
\text { Street }\end{array}$ \\
\hline $01 / 05$ & 0 & 0 & 0 & 0 & 0 & 0 & 0 & 0 & 0 & 0 & 0 \\
\hline $15 / 07$ & 75 & 36.20 & 36.27 & 35.80 & 34.46 & 37.75 & 35.50 & 38.70 & 35.94 & 39.42 & 43.17 \\
\hline $22 / 07$ & 82 & 37.83 & 38.03 & 37.81 & 35.92 & 38.78 & 36.15 & 40.95 & 37.95 & 39.48 & 43.30 \\
\hline $25 / 07$ & 85 & 39.81 & 39.46 & 38.93 & 36.66 & 39.89 & 37.63 & 42.18 & 39.23 & 40.09 & 43.32 \\
\hline $29 / 07$ & 89 & 40.95 & 40.26 & 39.64 & 37.34 & 40.52 & 38.12 & 42.46 & 40.16 & 40.13 & 43.66 \\
\hline $1 / 08$ & 92 & 42.71 & 41.57 & $\mathbf{3 9 . 7 7}$ & 38.16 & 41.45 & 38.89 & 42.72 & 40.55 & 40.26 & 43.74 \\
\hline $5 / 08$ & 96 & 43.11 & 43.18 & 39.38 & 38.99 & 42.38 & 39.21 & 44.00 & 41.44 & 40.39 & 43.77 \\
\hline $8 / 08$ & 99 & 43.81 & 44.18 & 38.99 & $\mathbf{4 0 . 1 1}$ & 43.14 & 39.10 & $\mathbf{4 4 . 3 9}$ & 41.69 & 40.53 & $\mathbf{4 4 . 0 9}$ \\
\hline $12 / 08$ & 103 & 44.77 & 45.97 & 38.24 & 40.00 & 44.45 & $\mathbf{3 9 . 5 6}$ & 44.05 & $\mathbf{4 2 . 2 5}$ & $\mathbf{4 0 . 7 1}$ & 43.93 \\
\hline $15 / 08$ & 106 & 45.38 & 47.87 & 36.71 & 39.61 & $\mathbf{4 4 . 7 1}$ & 38.61 & 42.49 & 41.17 & 40.70 & 43.83 \\
\hline $19 / 08$ & 110 & $\mathbf{4 5 . 9 2}$ & $\mathbf{4 8 . 6 6}$ & 36.30 & 39.29 & 43.75 & 38.29 & 42.26 & 40.86 & 40.47 & 43.78 \\
\hline $22 / 08$ & 113 & 45.81 & 47.38 & 36.03 & 39.16 & 42.90 & 38.22 & 42.11 & 40.34 & 40.30 & 43.50 \\
\hline $26 / 08$ & 117 & 44.88 & 46.07 & 35.96 & 38.74 & 42.43 & 38.17 & 42.02 & 40.32 & 40.19 & 43.32 \\
\hline $29 / 08$ & 120 & 44.35 & 45.09 & 35.95 & 38.32 & 42.16 & 38.10 & 41.90 & 40.20 & 40.09 & 43.16 \\
\hline $2 / 09$ & 124 & 44.08 & 44.47 & 35.86 & 38.21 & 41.12 & 38.01 & 41.71 & 40.17 & 40.02 & 42.93 \\
\hline $9 / 09$ & 131 & 42.94 & 44.09 & 35.83 & 38.09 & 40.73 & 37.91 & 41.71 & 40.17 & 39.98 & 42.86 \\
\hline $16 / 09$ & 138 & 42.03 & 43.28 & 35.78 & 37.72 & 39.67 & 37.81 & 41.64 & 40.17 & 39.89 & 42.82 \\
\hline $23 / 09$ & 145 & 41.02 & 41.89 & 35.40 & 37.47 & 38.33 & 37.62 & 41.50 & 40.06 & 39.70 & 42.54 \\
\hline
\end{tabular}

Note. The maximum average width values are shown in bold.

Fluctuations, in particular trends, are recorded by the wave formula ${ }^{8,12}$ of the form

$$
y_{i}=A_{i} \cos \left(\pi x / p_{i}-a_{8 i}\right), A_{i}=a_{1 i} x^{a_{2 i}} \exp \left(-a_{3 i} x^{a_{4 i}}\right), p_{i}=a_{5 i}+a_{6 i} x^{a_{7 i}},
$$

where $y$ - the index (dependent factor), $i$ - number components of the model (1), $m$ - number of members in the model (1), $x$ - explanatory variable (influencing factor), $a_{1} \ldots a_{8}$ - the parameters of the model (1) taking the numerical values in the course of structural-parametric identification in the software environment Curve Expert-1.40 (URL: http://www.curveexpert.net/), $A_{i}$ - amplitude (half) of wavelet (axis $y$ ), $p_{i}$ - the half-period fluctuations (axis $x$ ).

We exclude the measure ${ }^{15}$ of significance $0.05 \%$ and estimate the adequacy of the formulas by the correlation coefficient. All 10 statistical models came out with the adequacy of the above 0.999 .

Therefore, the dynamics of growth and decline of leaves has a high quantum certainty.

\section{RESULTS AND DISCUSSION}

Table 2 shows the parameters of the model (1) with two components, the first of which is a trend in the form of biotechnical law ${ }^{11}$. Cyclical fluctuations in 01.05.2018. halftime shows $a_{5 i}$. The halfperiod of oscillation at the beginning of the growing season for 10 birches varies from 1.32 (Panfilov street) to 21.35 days (Lebedev street).

Table 2: Models (1) dynamics of average width of birch leaves

\begin{tabular}{|c|c|c|c|c|c|c|c|c|c|}
\hline \multirow{3}{*}{$\begin{array}{c}\text { Number } \\
i\end{array}$} & \multicolumn{8}{|c|}{ Wavelet $y_{i}=a_{1 i} x^{a_{2 i}} \exp \left(-a_{3 i} x^{a_{4 i}}\right) \cos \left(\pi x /\left(a_{5 i}+a_{6 i} x^{a_{7 i}}\right)-a_{8 i}\right)$} & \multirow{3}{*}{$\begin{array}{c}\text { Coef. } \\
\text { corr. } \\
r\end{array}$} \\
\hline & \multicolumn{4}{|c|}{ The amplitude (half) the fluctuations } & \multicolumn{3}{|c|}{ The half-period of oscillations } & Shift & \\
\hline & $a_{1 i}$ & $a_{2 i}$ & $a_{3 i}$ & $a_{4 i}$ & $a_{5 i}$ & $a_{6 i}$ & $a_{7 i}$ & $a_{8 i}$ & \\
\hline \multicolumn{10}{|c|}{ Lebedev Street } \\
\hline 1 & $1.21685 \mathrm{e}-5$ & 9.17015 & 6.05278 & 0.32571 & 0 & 0 & 0 & 0 & \multirow{2}{*}{0.9995} \\
\hline 2 & 0.44598 & 0.48964 & 0.048008 & 0.79134 & 21.25481 & 0 & 0 & -2.85512 & \\
\hline
\end{tabular}




\begin{tabular}{|c|c|c|c|c|c|c|c|c|c|}
\hline 1 & 0.0040275 & 2.23873 & 0.00027388 & 1.77914 & 0 & 0 & 0 & 0 & \multirow[b]{2}{*}{0.9994} \\
\hline 2 & $\begin{array}{c}-1.06631 \mathrm{e}- \\
22\end{array}$ & 13.60735 & 0.074901 & 1.09307 & 18.25100 & $-4.10921 \mathrm{e}-5$ & 1.86324 & -3.10286 & \\
\hline \multicolumn{10}{|c|}{ Street Eshkinina } \\
\hline 1 & $4.37213 \mathrm{e} 7$ & 6.24840 & 21.67608 & 0.14738 & 0 & 0 & 0 & 0 & \multirow[b]{2}{*}{0.9998} \\
\hline 2 & $\begin{array}{c}-0.27508 \mathrm{e}- \\
17\end{array}$ & 11.50074 & 0.27033 & 0.85753 & 9.26474 & 0.0010104 & 1.76082 & -4.63677 & \\
\hline \multicolumn{10}{|c|}{ Lenin avenue } \\
\hline 1 & 0.021506 & 2.08161 & 0.035573 & 0.88346 & 0 & 0 & 0 & 0 & \multirow[b]{2}{*}{0.9999} \\
\hline 2 & $\begin{array}{c}-2.56548 \mathrm{e}- \\
24\end{array}$ & 14.15017 & 0.17309 & 0.90399 & 1.55507 & 0.0029436 & 1.41184 & 4.23812 & \\
\hline \multicolumn{10}{|c|}{ Chawain Boulevard } \\
\hline 1 & 0.079922 & 1.54159 & 0.00039496 & 1.65732 & 0 & 0 & 0 & 0 & \multirow[b]{2}{*}{50.9997} \\
\hline 2 & $\begin{array}{c}-4.74722 \mathrm{e}- \\
30\end{array}$ & 17.78349 & 0.055937 & 1.20232 & 14.57925 & 0.00056749 & 1.68957 & -1.52615 & \\
\hline \multicolumn{10}{|c|}{ Panfilov Street } \\
\hline 1 & $3.66251 \mathrm{e} 6$ & 7.38171 & 21.73815 & 0.16016 & 0 & 0 & 0 & 0 & \multirow{2}{*}{0.9998} \\
\hline 2 & -1.03801 & 1.08360 & 1.48447 & 0.27784 & 1.31728 & 0.023483 & 1.07558 & 0.91434 & \\
\hline \multicolumn{10}{|c|}{ Karl Marx Street } \\
\hline 1 & $1.31774 \mathrm{e} 6$ & 7.87565 & 21.57557 & 0.16721 & 0 & 0 & 0 & 0 & \\
\hline 2 & $-5.06517 e-6$ & 4.54130 & 0.83355 & 0.50876 & 15.76053 & 0.00020116 & 1.98175 & -4.85485 & \\
\hline \multicolumn{10}{|c|}{ Builders Street } \\
\hline 1 & $1.86986 \mathrm{e} 6$ & 9.10854 & 24.13993 & 0.16944 & 0 & 0 & 0 & 0 & \multirow[b]{2}{*}{70.9998} \\
\hline 2 & $\begin{array}{c}-7.26191 \mathrm{e}- \\
19\end{array}$ & 11.79845 & 0.26301 & 0.83912 & 13.57641 & 0.0017335 & 1.61783 & -3.64787 & \\
\hline \multicolumn{10}{|c|}{ Botanical garden } \\
\hline 1 & 6.59123 & 0.52516 & 0.013763 & 0.82177 & 0 & 0 & 0 & 0 & \multirow[b]{2}{*}{1.0000} \\
\hline 2 & $\begin{array}{c}-1.28495 \mathrm{e}- \\
21 \\
\end{array}$ & 12.70989 & 0.13276 & 0.97603 & 20.55353 & 0.00012933 & 1.60894 & -0.35495 & \\
\hline \multicolumn{10}{|c|}{ Osipenko Street } \\
\hline 1 & $8.05960 \mathrm{e} 8$ & 3.85974 & 20.58087 & 0.11220 & \begin{tabular}{|l|}
0 \\
\end{tabular} & 0 & 0 & \begin{tabular}{|l|}
0 \\
\end{tabular} & \multirow{2}{*}{1.0000} \\
\hline 2 & -0.049369 & 0.83696 & 1.13220 & 0.15655 & 9.57983 & 0.10275 & 0.82053 & -5.58996 & \\
\hline
\end{tabular}

Figures 1 and 2 show the graphs of the two-term formula according to table 2 . They are all the same in design, but have different patterns of change over time. Then it can be argued that the dynamics of the parameters of birch leaves hanging during the growing season near the maximum increment is very highly adequate with a correlation coefficient of more than 0.999 , that is, the average behavior of 10 leaves has a quantum certainty. But meteorological parameters during the growing season of the birch have a strong quantum entanglement. Then in the future it is necessary to understand how the birch leaves for 180 million. have years of evolution gained such high vibrational adaptability? It feels as if they understand and lead their vegetative organs consciously to changes in the surrounding group of accounting leaves environment.

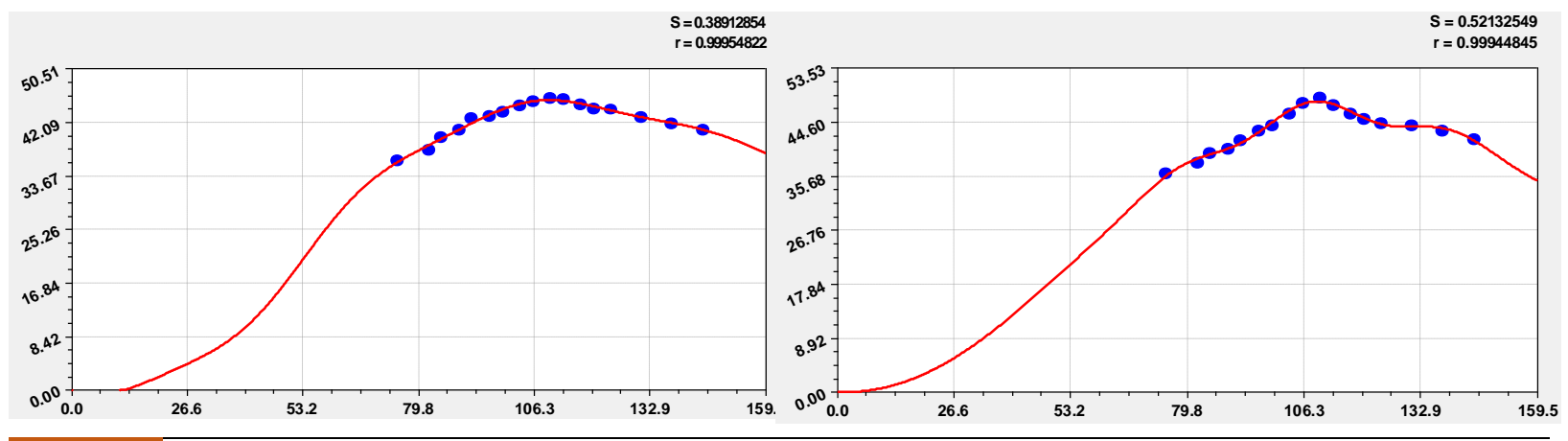

276 JECET; June 2019- August 2019; Sec. A; Val.8. №.3, 273-280.

DOI:10.24214/jecet.A.8.3.27380. 
Lebedev Street

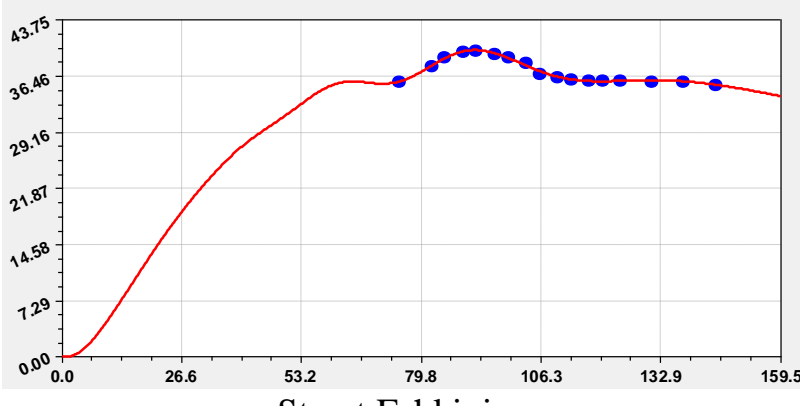

Street Eshkinina
Voskresensky prospect

$S=0.23800668$
$r=0.99987931$

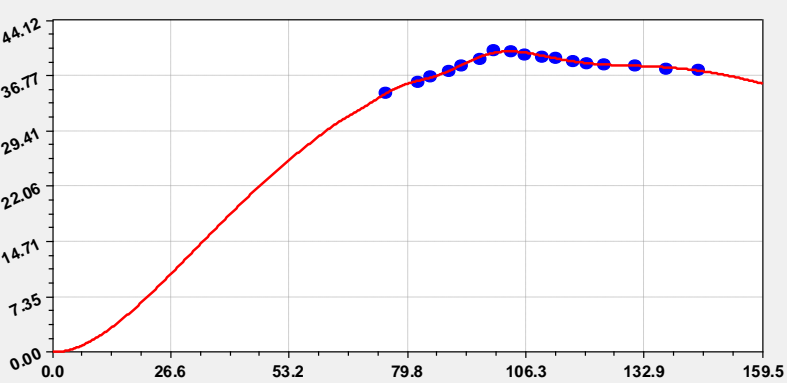

Lenin avenue

Fig. 1: Graphs of the dynamics of the average width of the group of 10 leaves of birch

To assess the behavior of leaf groups, we introduce a new criterion - the coefficient of dynamism equal to the ratio of the difference between the fact and the trend to the fact of the average width (tab. 3). The maximum width of the leaves and gave the highest values of the coefficient of dynamism.

Table 3: The coefficient of dynamic growth of the leaves of the silver birch

\begin{tabular}{|c|c|c|c|c|c|c|c|c|c|c|c|}
\hline Date & $\begin{array}{c}\text { Time } \\
t \text {, day }\end{array}$ & $\begin{array}{c}\text { Lebedev } \\
\text { Street }\end{array}$ & $\begin{array}{c}\text { Voskresensky } \\
\text { prospect }\end{array}$ & $\begin{array}{c}\text { Street } \\
\text { Eshkinina }\end{array}$ & $\begin{array}{c}\text { Lenin } \\
\text { avenue }\end{array}$ & $\begin{array}{c}\text { Chawain } \\
\text { Boulevard }\end{array}$ & Panfilov & K.Marx & Builders & BotanicalOsipenko \\
Street & Street & garden & Street \\
\hline $01 / 05$ & 0 & - & - & - & - & - & - & - & - & - & - \\
\hline $15 / 07$ & 75 & 0.0127 & 0.0331 & -0.0371 & 0.0050 & 0.0078 & -0.0098 & -0.0281 & -0.0151 & -0.0007 & 0.0007 \\
\hline $22 / 07$ & 82 & -0.0336 & -0.0168 & 0.0028 & -0.0069 & -0.0224 & -0.0259 & -0.0064 & -0.0090 & -0.0097 & -0.0046 \\
\hline $25 / 07$ & 85 & -0.0123 & -0.0143 & 0.0274 & -0.0050 & -0.0134 & 0.0035 & 0.0118 & 0.0079 & 0.0022 & -0.0065 \\
\hline $29 / 07$ & 89 & -0.0176 & -0.0344 & 0.0414 & -0.0076 & -0.0194 & 0.0043 & 0.0064 & 0.0133 & -0.0005 & -0.0009 \\
\hline $1 / 08$ & 92 & 0.0041 & -0.0275 & $\mathbf{0 . 0 4 3 1}$ & 0.0009 & -0.0098 & 0.0169 & 0.0054 & 0.0119 & 0.0005 & -0.0002 \\
\hline $5 / 08$ & 96 & -0.0084 & -0.0174 & 0.0333 & 0.0078 & -0.0013 & 0.0177 & 0.0276 & 0.0217 & 0.0015 & -0.0001 \\
\hline $8 / 08$ & 99 & -0.0048 & -0.0115 & 0.0244 & $\mathbf{0 . 0 2 7 0}$ & 0.0089 & 0.0110 & $\mathbf{0 . 0 3 2 7}$ & 0.0209 & 0.0038 & $\mathbf{0 . 0 0 7 2}$ \\
\hline $12 / 08$ & 103 & 0.0047 & 0.0106 & 0.0076 & 0.0155 & 0.0317 & $\mathbf{0 . 0 1 8 9}$ & 0.0224 & $\mathbf{0 . 0 2 7 5}$ & $\mathbf{0 . 0 0 7 3}$ & 0.0042 \\
\hline $15 / 08$ & 106 & 0.0122 & 0.0408 & -0.0311 & 0.0009 & $\mathbf{0 . 0 3 4 8}$ & -0.0067 & -0.0142 & -0.0014 & 0.0068 & 0.0028 \\
\hline $19 / 08$ & 110 & $\mathbf{0 . 0 1 9 8}$ & $\mathbf{0 . 0 4 8 7}$ & -0.0381 & -0.0115 & 0.0134 & -0.0155 & -0.0191 & -0.0115 & 0.0013 & 0.0033 \\
\hline $22 / 08$ & 113 & 0.0170 & 0.0203 & -0.0417 & -0.0165 & -0.0041 & -0.0167 & -0.0211 & -0.0250 & -0.0024 & -0.0015 \\
\hline $26 / 08$ & 117 & -0.0007 & -0.0068 & -0.0372 & -0.0276 & -0.0095 & -0.0158 & -0.0197 & -0.0244 & -0.0039 & -0.0032 \\
\hline $29 / 08$ & 120 & -0.0084 & -0.0249 & -0.0320 & -0.0375 & -0.0096 & -0.0151 & -0.0190 & -0.0254 & -0.0052 & -0.0047 \\
\hline $2 / 09$ & 124 & -0.0061 & -0.0300 & -0.0266 & -0.0368 & -0.0238 & -0.0131 & -0.0176 & -0.0221 & -0.0050 & -0.0068 \\
\hline $9 / 09$ & 131 & -0.0108 & -0.0121 & -0.0119 & -0.0289 & -0.0068 & -0.0054 & -0.0044 & -0.0114 & -0.0015 & -0.0019 \\
\hline $16 / 09$ & 138 & -0.0031 & 0.0082 & 0.0039 & -0.0226 & 0.0015 & 0.0050 & 0.0101 & 0.0031 & 0.0020 & 0.0045 \\
\hline $23 / 09$ & 145 & 0.0083 & 0.0262 & 0.0120 & -0.0085 & 0.0096 & 0.0154 & 0.0253 & 0.0179 & 0.0040 & 0.0061 \\
\hline
\end{tabular}

Note. The maximum dynamic factor values are shown in bold.

This criterion allows to rank the birch in descending order of the influence of fluctuations.
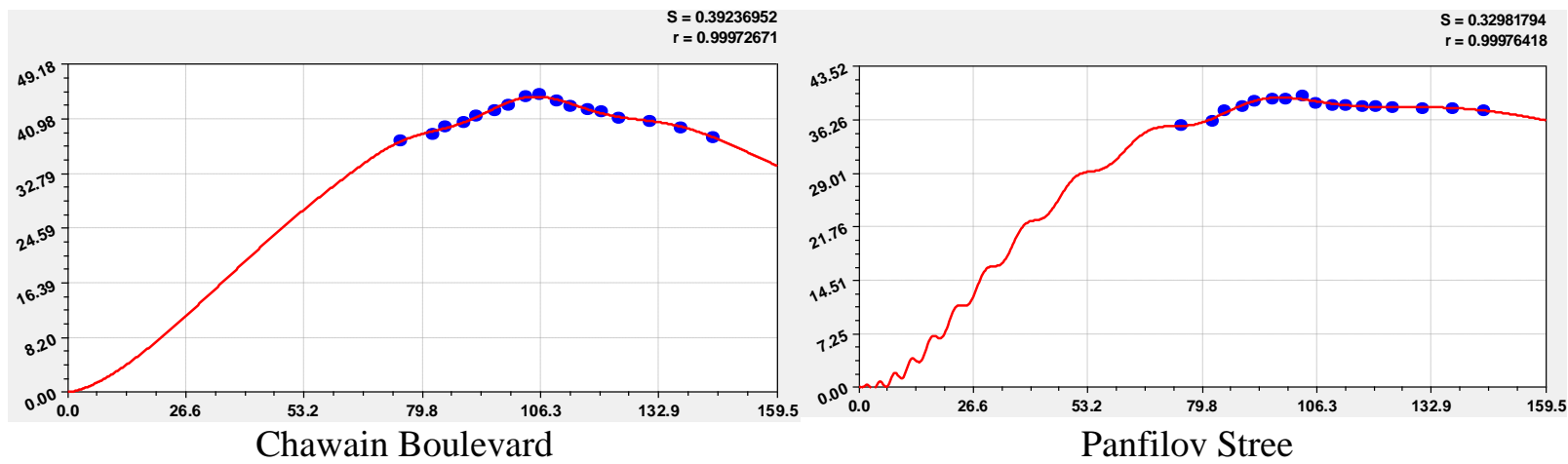

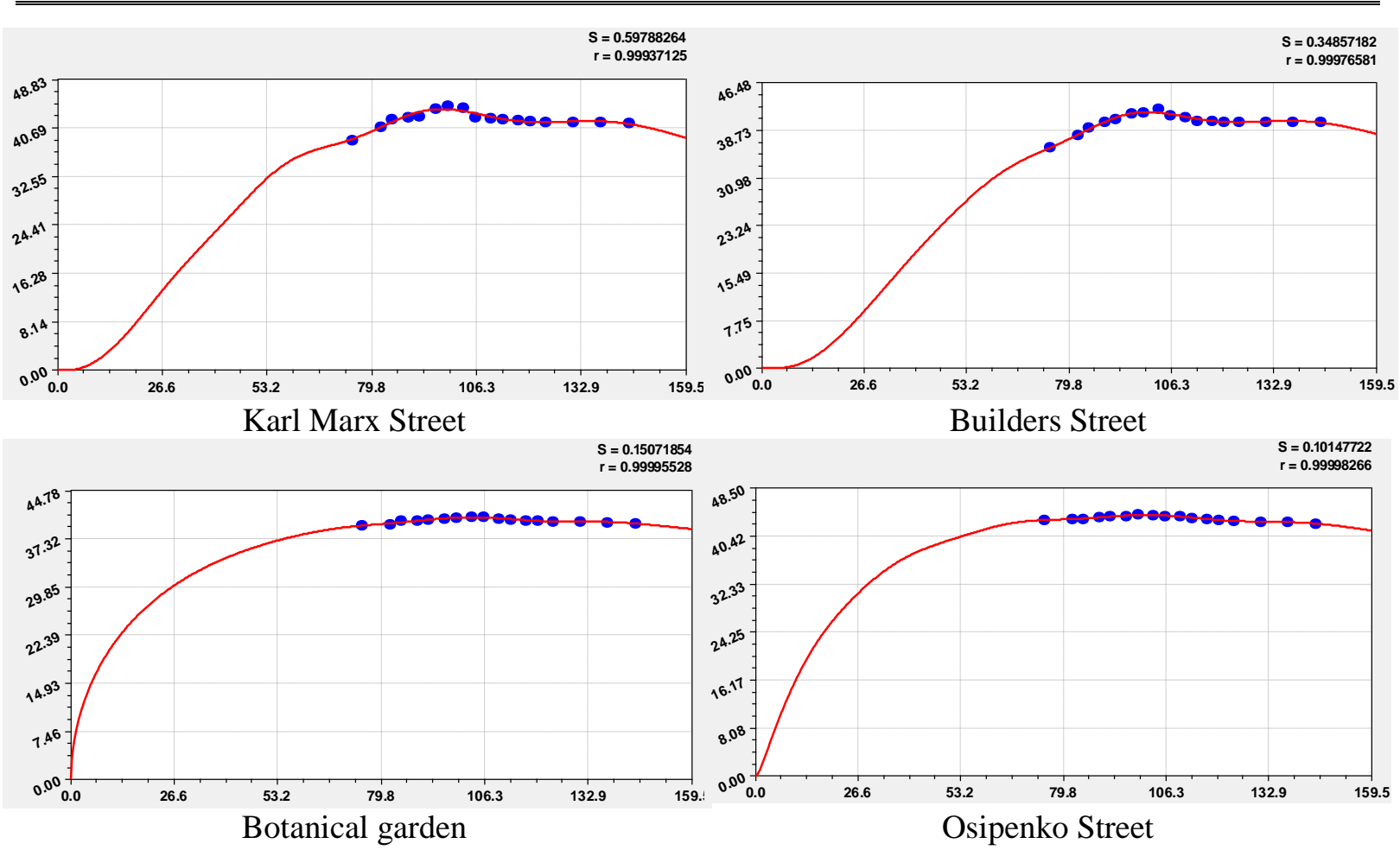

Fig. 2: Graphs of the dynamics of the average width of the group of 10 leaves of birch

According to table 3, places for deterioration of conditions are distributed as follows: 1) 0.0072 Osipenko street, where there are almost no cars; 2) 0.0073 - Botanical garden, very little influence of the fence around the object; 3) 0.0189 - Panfilov street; 4) 0.0198 - Lebedev street; 5) 0.0270 - Lenin Avenue; 6) 0.0275 - Builders street; 7) 0.0327 - Karl Marx street; 8) 0.0438 - Chavain Boulevard; 9) 0.0431 - Eshkinina street; 10) 0.0487 - Voskresensky Prospect.

So what is better, a quiet life with a low coefficient of dynamism, or the largest increment of the average width of the leaves of birch hanging? On average the maximum width of the sheet from the table, 1 birch in the deterioration of productivity is as follows: 1) $48.66 \mathrm{~mm}$ - Voskresensky prospect; 2) $45.92 \mathrm{~mm}$ is the street Lebedev; 3) $44.71 \mathrm{~mm}$ Boulevard Chavain; 4) $44.39 \mathrm{~mm}$ - street Karla Marksa; 5) $44.09 \mathrm{~mm}$ - Osipenko street; 6) $42.25 \mathrm{~mm}$ - the street of Builders, 7) $40.71 \mathrm{~mm}$ Botanical garden; 8) $40.11 \mathrm{~mm}$ - Prospekt Laziness-on; 9) $39.77 \mathrm{~mm}$ street Eshkinina; 10) $39.56 \mathrm{~mm}$ - Panfilov's street. Of course, the growth of increments and the achievement of the average maximum width of the leaves affects the own physiological state of the tree. For example, a birch with productive leaves according to table 1 for four days from 15.08 to 19.08 changed the average width of leaves on Voskresensky Avenue from 47.87 to $48.66 \mathrm{~mm}$ or had an increment rate (48.66 - 47.87) / 4 $=0.198 \mathrm{~mm}$. And on Panfilov street the average growth rate of leaf width is $(39.56-39.10) / 4=$ $0.115 \mathrm{~mm}$.

As is known, environmental monitoring is carried out for a variety of types of pollution, the content of which in air, water and soil should not exceed the maximum permissible concentrations. However, indirect monitoring through the behavior of birch leaves hanging in the growing season allows without measuring the concentrations of pollution to conduct an environmental assessment of the territory of the place of growth of the birch. As a result, birch leaves react to all changes in the environment of birch, and take into account the effects that are still unknown to man. This is the essence of our methods of environmental indication and patent 2606189 becomes a pioneering solution. 
To be accepted as criteria for the environmental assessment of the rate of increment, it is necessary to take into account the physiological parameters of the tree, for example, classes of sanitary state, age and more. Thus, to indicate the environment around birch's recommended ratio of dynamism, with a maximum of medium size account leaves.

\section{CONCLUSION}

The 2606189 patent for invention from the side at a height of 1.5 to $2.0 \mathrm{~m}$ from the side of the prevailing winds on the dynamics from 15 July to 23 September 2018 measured average width of 10 account leaves around the road. The parameters of the model with two components showed that the half-period of oscillation at the beginning of the growing season for 10 birches varies from 1.32 to 21.35 days. All models of dynamics are the same in design, but have a different character. The growing season near the maximum growth affects with a correlation coefficient of more than 0.999, so the behavior of 10 leaves has quantum certainty.

To evaluate the behavior of leaf groups, a new criterion is introduced - the coefficient of dynamism equal to the ratio of the difference between the fact and the trend to the fact of the average width. The maximum width of the leaves and gave the highest values of the coefficient of dynamism. This criterion allows to rank the birch in descending order of the influence of vibration influence of the environment.

\section{REFERENCES}

1. V. Zharkova, The solar magnet field and the terrestrial climate. URL: https://watchers.news/2018/11/11/Valentina-Zharkova-solar-magnet-field-and-terrestrialclimate-presentation/ (Дата обращения 01.03.2019).

2. V.V. Korona, A.G. Vasilyev, Structure and variability of plant leaves: fundamentals of modular theory. Ekaterinburg: Uro ran, 2007. 280 PP.

3. G.L. Foster, D.L. Royer, D.J. Lunt Future climate forcing potentially without precedent in the last 420 million years // 2017. Nature communications | 8:14845 | DOI: 10.1038/ncomms 14845 |www.nature.com/naturecommunications

4. M. Maarit, Impacts of temperature and ozone on carbon retention processes of birch and aspen Dissertations in Forestry and Natural Sciences. Finland, Joensuu, on June, 08, 2012, 54 p.

5. Mapping tree density at a global scale / T. W. Crowther, et. al. Nature 525, 201-205 (2015); doi:10.1038/nature14967. $13 \mathrm{p}$.

6. Tree rings reveal globally coherent signature of cosmogenic radiocarbon events in 774 and 993 CE / U. Büntgen, et al. NATURE COMMUNICATIONS | (2018) 9:3605 | DOI: 10.1038/s41467018-06036-0. $7 \mathrm{p}$.

7. P. M. Mazurkin, A. I. Kudryashova Quanta of behavior of meteorological parameters on three-hour measurements in the growing season of birch / / American Scientific Journal № 2019, (24) / P. 59-75.

8. P.M. Mazurkin, Wavelet Analysis Statistical Data. Advances in Sciences and Humanities. Vol. 1, No. 2, 2015, pp. 30-44. doi: 10.11648/j.ash.20150102.11.

9. P.M. Mazurkin, A.I. Kudryashova, Factor analysis of annual global carbon dynamics (according to Global_Carbon_Budget_2017v1.3.xlsx). Materials of the International 
Conference "Research transfer" - Reports in English (part 2). November 28, 2018. Beijing, PRC. P.192-224.

10. Y. Zhang, L. Bielory, P. Georgopoulos, Climate change effect on Betula (birch) and Quercus (oak) pollen seasons in US // Int J Biometeorol. 2014 July; 58(5): 909-919. doi:10.1007/s00484-013-0674-7.

11. P.M. Mazurkin, Method of identification. (2014). International Multidisciplinary Scientific GeoConference Surveying Geology and Mining Ecology Management, SGEM, 1 (6), pp. $427-$ 434.https://www.scopus.com/inward/record.uri?eid=2-s2.0-84946541076\&partnerI $\quad \mathrm{D}=40$ \&md5=72a3fcce31b20f2e63e4f23e9a8a40e3

12. P.M. Mazurkin, Identification of the wave patterns of behavior., International Multidisciplinary Scientific GeoConference Surveying Geology and Mining Ecology Management, SGEM, 2014, 1 (6), pp. 373-380. https://www.scopus.com/ inward/record.uri ?eid=2-s2.0-84946550468\&partnerID=40\&md5=0fd8f91ed5b1 f0592fc587e 5ffb14e51

13. C.A. Polgar, R.B. Primack, Leaf-out phenology of temperate woody plants: from trees to ecosystems // New Phytologist, 2011, 191: 926-941. doi: 10.1111/j.1469-8137.2011.03803

14. M. Rousi, J. Pusenius, Variations in phenology and growth of European white birch (Betula Pendula) clones // 2005. Heron Publishing - Victoria, Canada. Tree Physiology 25, 201-210

15. L.R. Wasserstein, et.al. Moving to a World Beyond " $p<0.05$ ", The American Statistician, 2019, 73:sup1, 1-19, DOI: 10.1080/00031305.2019.1583913.

* Corresponding Authors: Mazurkin P.M'1 and Kudryashova A.I ${ }^{2}$.

${ }^{1}$ Dr. Sc., Prof., Volga State University of Technology, Yoshkar-Ola, Russia, ${ }^{2}$ S. lec., Volga State University of Technology, Yoshkar-Ola, Russia 